\title{
Translações no Facebook: a controvérsia “Galo Machista"!? nas páginas de torcidas organizadas
}

\author{
Translations in Facebook: male chauvinism and other issues \\ during a controversy in Brazilian football
}

\author{
Carlos d'Andréa \\ Universidade Federal de Minas Gerais (UFMG), Belo Horizonte / Brasil \\ Doutorado em Estudos Linguísticos, UFMG \\ carlosfbd@gmail.com \\ Leonardo Melgaço \\ Graduando em Comunicação Social pela UFMG \\ Roberta Firmino \\ Graduanda em Comunicação Social pela UFMG
}

\begin{abstract}
RESUMo: 0 ponto de partida deste trabalho é a controvérsia em torno da exploração do corpo feminino e do machismo no futebol desencadeada pelo desfile de lançamento do novo uniforme do Clube Atlético Mineiro, em fevereiro de 2016. Nosso objetivo no artigo é mapear e discutir as translações entre torcedores e demais atores nas páginas do Facebook de cinco torcidas organizadas do time. Mais especificamente, nos interessa observar, através da extração e visualização de rastros digitais extraídos do Facebook, como a controvérsia "Galo Machista"!? desencadeou a formação de agrupamentos, oposições, alianças etc. entre usuários/torcedores envolvidos nas discussões on-line. Partindo da abordagem da Teoria Ator-Rede, nos apropriamos de conceitos como translação e controvérsia, que são discutidos a partir da ambiência sociotécnica do Facebook e das especificidades das torcidas organizadas. Após uma análise quantitativa das postagens, detalhamos as discussões desencadeadas por uma "nota de repúdio" ao desfile (torcida Galo Marx) e por uma peça de apoio à patrocinadora (Galo Metal).
\end{abstract}

PalaVRas-CHAVE: Futebol; Controvérsia; Machismo; Facebook; Métodos digitais.

ABSTRACT: The starting point of this work is the controversy about the exploitation of the female body and sexism in football triggered by the launch of the brazilian team Clube Atlético Mineiro new uniform in February 2016. Our objective in this article is to discuss the translations between the actors on the Facebook pages of five Atletico's fans associations. Specifically, we are interested in observing, through the extraction and visualization of digital traces taken from Facebook, how the controversy triggered the formation of colletives, oppositions, alliances etc. between fans and others actors involved in online discussions. Based in the Actor-Network Theory approach, we discuss concepts such as translation and controversy, as well as the sociotechnical ambience of Facebook and the specifics of the fan's associations in Brazil. After a quantitative analysis, we detail the discussions triggered by two posts: a "repudiation note" published by the "Galo Marx" association and by a institutional piece supporting the sponsor and the team published by "Galo Metal".

KEYWORDS: Football; Controversy; Male chauvinism; Facebook; Digital methods. 


\section{INTRODUÇ̃̃o}

Na noite de 15 de fevereiro de 2016, o Clube Atlético Mineiro (CAM) lançou seu novo uniforme para a temporada, e outros materiais esportivos, em um desfile em Belo Horizonte. A festa marcou o início da parceria com a fornecedora de material esportivo Dry World e contou com a presença do jogador Robinho, contratado no início de 2016.0 evento, no entanto, ficou marcado por uma intensa discussão em torno da exploração do corpo feminino: várias modelos jovens desfilaram de biquíni, enquanto homens trajavam o novo uniforme completo.

A discussão na internet se aqueceu já na madrugada do dia 16, quando foram publicadas duas notas de repúdio (pela torcida Galo Marx e pelo blog CAMikaze, vinculado à ESPN). Nesta segunda nota, por exemplo, 21 torcedoras afirmaram: "Não podemos aceitar que a imagem feminina seja tratada como peça de enfeite de estádio, encomendadas para agradar o público masculino - que, há muito, deixou de ser único protagonista no universo do futebol". ${ }^{1}$ No dia seguinte ao desfile, outra polêmica veio à tona: as etiquetas de algumas camisas da empresa canadense Dry World traziam a frase "Give it to your wife" ("entregue a camisa à sua esposa") nas instruções de lavagem.

O acontecimento ganhou ampla repercussão nas redes sociais on-line e na imprensa esportiva, alavancando discussões de temas como machismo e sexismo no futebol e fora dele. Torcedores e torcedoras que criticavam a postura do time se reuniram em torno de hashtags como \#galomachista e \#MeuFutebolNãoTemPúblicoAlvo. Preocupados com os impactos da controvérsia sobre a atuação do time, que faria sua estreia na Copa Libertadores da América dois dias após o desfile, parte da torcida saiu em defesa do clube e de seus parceiros comerciais. A lucrativa parceria do time com a Dry World, por exemplo, foi lembrada através da hashtag \#FechadoComADryWorld. Este slogan de apoio foi usado, entre outros, por 12 torcidas organizadas do CAM, que em janeiro de 2016 haviam formado o movimento "Unidos pelo Galo".

Consideramos que, de acordo com os preceitos teórico-metodológicos da Teoria Ator-Rede, as discussões desencadeadas pelo desfile podem ser tomadas como uma controvérsia, uma vez que o acontecimento fez emergir novas associações entre atores

\footnotetext{
${ }^{1}$ CAMPOS. Nota de repúdio: machismo em evento do Galo, s/ p.
} 
ligados aos temas em questão (futebol, machismo, feminismo etc.), revelando a complexidade de "social" em formação. Assim, nosso objetivo neste artigo é mapear e discutir as translações entre torcedores e demais atores nas discussões sobre a controvérsia “Galo Machista”!? nas páginas do Facebook de cinco torcidas organizadas do Clube Atlético Mineiro. Mais especificamente, nos interessa observar, a partir de rastros digitais extraídos das páginas, como a controvérsia desencadeou a formação de agrupamentos, oposições, alianças etc. entre usuários do Facebook envolvidos nas discussões.

Iniciamos o artigo discutindo, a partir de Latour (2012), as perspectivas da Teoria Ator-Rede (TAR) sobre a formação do social. Na abordagem proposta destacam-se os conceitos de translação (Callon, 1986) e controvérsia (Venturini; Latour, 2010). As especificidades do Facebook e das torcidas organizadas de futebol são também abordadas. Baseado na proposta dos "métodos digitais" de pesquisa (Rogers, 2015), extraímos através do software Netvizz rastros digitais (curtidas, comentários e compartilhamentos) deixados por usuários em cinco páginas de torcidas organizadas no Facebook: Galo Marx, Galo Metal, Galoucura, 105 Minutos e Galo Queer. Na análise, as visualizações de grafos e outros dados relativos às postagens sobre a controvérsia nos ofereceram indícios sobre as associações entre os atores/torcedores. Em seguida, apresentamos dados qualitativos sobre as discussões na "nota de repúdio" publicada pela Galo Marx e na peça de apoio à patrocinadora postada pela Galo Metal. Ao final, apontamos como a desestabilização promovida pela controvérsia "Galo Machista"!? resultou em novos agrupamentos nas páginas do Facebook e discutimos como os debates analisados nos ajudam a compreender o machismo e outras práticas excludentes no futebol.

\section{SOCIAL EM FORMAÇÃO: TRANSLAÇÕES E CONTROVÉRSIAS}

"Que vem a ser uma sociedade? Que significa a palavra 'social'? Porque se diz que determinadas atividades apresentam uma "dimensão social"?"2 É a partir de questões como essas que Bruno Latour revisou e sistematizou as propostas - e provocações elaboradas nas três décadas anteriores pela chamada "sociologia das associações". Também conhecida como Teoria Ator-Rede, o construto teórico-metodológico elaborado por Latour, Michel Callon e outros tantos autores deixou de ser uma referência apenas

\footnotetext{
${ }^{2}$ LATOUR. Reagregando o social, p. 19.
} 
nos estudos de Ciência, Tecnologia e Sociedade (STS, em inglês) e hoje é um importante aporte para diferentes campos do conhecimento, em eles a Comunicação (Lemos, 2013).

Entre outros aspectos, a abordagem da Teoria Ator-Rede provoca o pesquisador a olhar para o "social" não como algo dado a priori, mas sim como resultado de associações contínuas entre atores humanos e não-humanos que compõem e recompõem redes a partir de suas ações. A agência de cada ator, ou actante, tem sempre uma dimensão coletiva, o que quer dizer que cada ator é a rede com a qual ele se associa, e que sua força está na capacidade de mediar, ou de fazer outros atores agirem junto com ele.

Latour (2012) aponta cinco fontes de incerteza para as pesquisas inspiradas pela Teoria Ator-Rede, ou "sociologia das associações" Interessa-nos especialmente na presente discussão a primeira dessas fontes de incerteza: "Não há grupos, apenas formação de grupos". O autor critica a chamada "sociologia do social" (de tradição durkheimiana) por se concentrar em grupos e categorias tomados como pressupostos a partir de rótulos e fronteiras definidos sem ouvir e acompanhar a movimentação dos atores e dos (re)agrupamentos compostos por eles. Se, como aponta Latour, "relacionarse com um ou outro grupo é um processo sem fim constituído por laços incertos, frágeis, controvertidos e mutáveis", 3 deve-se estar atento às movimentações e articulações dos atores, em especial nos momentos de incerteza e desestabilização das redes.

Em termos metodológicos, isso implica, por exemplo, em deixar que os próprios atores delimitem e nomeiem seus agrupamentos, o que ocorre em geral através da delegação a porta-vozes. Isso é possível na medida em que "grupos não são coisas silenciosas, mas o produto provisório de um rumor constante feito por milhões de vozes contraditórias sobre o que vem a ser um grupo e quem pertence a ele",4 ou seja, evidenciar e problematizar os próprios agrupamentos são atividades fundamentais nos agenciamentos dos atores-rede a partir da controvérsia que os mobiliza. Esse processo se dá por alinhamento ou oposição, isto é, a separação entre aliados e oponentes acontece na medida em que os atores tentam se diferenciar ou se aproximar uns dos outros. Além disso, é diretamente vinculado à performance dos atores, pois é através da ação deles que os grupos são feitos, desfeitos ou mantidos, refeitos.

\footnotetext{
${ }^{3}$ LATOUR. Reagregando o social, p. 50.

4 LATOUR. Reagregando o social, p. 55.
} 
Agir e fazer com que os outros ajam é o que resulta na formação de redes e de agrupamentos, o que torna fundamental a noção de translação. Segundo Freire (2005),

traduzir (ou transladar) significa deslocar objetivos, interesses, dispositivos, seres humanos. Implica desvio de rota, invenção de um elo que antes não existia e que de alguma maneira modifica os elementos imbricados. As cadeias de tradução referem-se ao trabalho pelo qual os atores modificam, deslocam e transladam os seus vários e contraditórios interesses. ${ }^{5}$

Callon (1986) chama a atenção para os movimentos de translação durante os processos associativos entre os atores. Visando conquistar aliados - e isolar os oponentes -, um ator-rede translada outros, por exemplo, ao identificar um problema e se tornar um ponto obrigatório de passagem, isto é, ao ser reconhecido como uma referência indispensável na rede em formação em torno da questão de interesse comum. Além disso, aponta Callon, o processo de translação passa pela atribuição de papéis para atores envolvidos e pela garantia da representatividade dos porta-vozes. Não censurar os atores quando eles falam sobre si mesmos ou sobre o ambiente social, respeitar a simetria entre aspectos técnicos e sociais (não mudando a forma de registrá-los) e observar a maneira como os atores definem e associam os diferentes elementos que utilizam para construir e explicar o mundo são os três princípios metodológicos apontados por Callon para estudos de cadeias de translações. Na perspectiva da Teoria Ator-Rede, o momento privilegiado para observação da formação do social - e, por consequência dos processos de translação que resultam em grupos emergentes - é o desenrolar de controvérsias. Conforme Venturini (2010), uma controvérsia é "onde a vida coletiva se torna mais complexa: onde a maior e mais diversa seleção de atores está envolvida; onde as alianças e oposições se transformam sem muita prudência; onde nada é tão simples quanto parece; onde todos estão gritando e brigando; onde conflitos crescem de maneira áspera". ${ }^{6}$

Callon, Lascoumes e Y. Barthe (2011) destacam o "poder das controvérsias sociotécnicas para revelar a multiplicidade de interesses associados a uma questão, mas também para fazer visível e passível de debate a rede de problemas que a questão evidencia".7 Nesse processo marcado pelas "incertezas de agrupamentos", há um

\footnotetext{
${ }^{5}$ FREIRE. Seguindo Bruno Latour: notas para uma antropologia simétrica, p. 51.

${ }^{6}$ VENTURINI. Diving in magma: how to explore controversies with actor-network theory, p. 262.

7 CALLON; LASCOUMES; BARTHE. Acting in an uncertain world, p. 31.
} 
reposicionamento dos atores com o intuito de compor novas coletividades e explorar novos "mundos possíveis". ${ }^{8}$

Consideramos que, na contemporaneidade, as redes sociais on-line podem ser tomadas como lócus privilegiados para a emergência e resignificação de controvérsias. Conforme Marres e Moats (2015), a potencialidade das mídias sociais para a análise de controvérsias deve-se tanto à crescente relevância empírica das mídias digitais para compreensão das questões sociais quanto pelo fato de tornarem acessíveis dados semiestruturados mais ricos do que a World Wide Web em geral (este segundo aspecto será retomado à frente nas discussões metodológicas)

Especificamente no caso do Facebook, destacam-se as especificidades desse ambiente sociotécnico não apenas para abrigar discussões em torno de temas variados, mas também todo um esforço institucionalizado para que, através das agências híbridas entre humanos e não-humanos (algoritmos, em especial), emerja um fórum que induza uma crescente participação dos atores. Conforme apontam Gerlitz and Helmond (2013) ao discutir a "economia do like" do Facebook, esse ambiente "utiliza uma retórica de socialidade e conectividade para criar uma infraestrutura em que a interatividade social e a afetação dos usuários são instantaneamente transformadas em dados valoráveis de consumidores e entram em ciclos múltiplos de multiplicação e intercâmbio". ${ }^{9}$

No que tange às discussões em torno de controvérsias, destacam no Facebook a presença de recursos como "respostas" e "curtidas" de comentários, que possibilitam que, em associação com esses atores não-humanos, mais usuários participem de diferentes formas dos debates travados on-line, multiplicando as formas de associação e translação e complexificando as redes em formação. Curtir um comentário, por exemplo, significa se alinhar à posição de outro ator, atribuindo a ele temporariamente o papel de porta-voz. Além disso, um comentário mais curtido e/ou mais respondido tende a ser exibido primeiro quando os comentários são hierarquizados por "top comments". Isso significa que, em função das prioridades filtradas pelos algoritmos, no Facebook a busca por visibilidade passa pela capacidade de fazer com que outros atores ajam (curtindo, respondendo) a partir de suas ações, possibilitando diferentes formas de transladar.

\footnotetext{
${ }^{8}$ CALLON; LASCOUMES; BARTHE. Acting in an uncertain world, p. 28.

${ }^{9}$ GERLITZ; HELMOND. The like economy: Social buttons and the data-intensive web, p. 1349.
} 


\section{TORCIDAS ORGANIZADAS: GRUPOS EM FORMAÇÃO?}

Pensemos no caso das torcidas organizadas de futebol. Ainda que a maioria delas tenham mecanismos e procedimentos que estimulem a formalização e o fortalecimento dos vínculos entre os afiliados, acreditamos ser possível observá-las como agrupamentos em constante rearranjo, principalmente - mas não exclusivamente - nos ambientes digitais.

Toledo (2012), ao discutir as mudanças nas torcidas organizadas a partir dos anos 1990, identifica uma crescente associação das torcidas organizadas, principalmente pelo poder público e pela cobertura jornalística, com a violência urbana, intensificando uma lógica de criminalização da periferia das grandes cidades brasileiras. Questionando uma percepção de que as torcidas organizadas formariam "grupos homogêneos, autocontidos e orientados para o bandidismo",10 o autor identifica um "certo esgarçamento dos projetos coletivos mais tradicionais que animaram os coletivismos dos torcedores".11 Essa fragmentação, aponta o Toledo, não significou uma "despolitização generalizada das torcidas organizadas", mas sim "uma reorientação de vontades políticas" que dialogavam com um conjunto de transformações no país e no futebol. Também nesse contexto, ganhavam espaço formas de torcer mais atreladas à crescente mercantilização do futebol, entre as quais a ideia do "sócio torcedor" e do "torcedor consumidor".

Já Silva (2012), ao pesquisarem, entre 2008 e 2009, as torcidas organizadas (TOs) em Belo Horizonte, apontam que, embora haja alguns traços comuns entre os filiados - a maioria são homens solteiros, por exemplo -, há diferenças significativas entre os agrupamentos de um mesmo time. Considerando que "a participação em uma TO implica a aceitação de normas e ideologias as quais podem até extrapolar o futebol",12 os autores identificam inclusive a existência de conflitos entre torcidas de um mesmo time por questões políticas e ideológicas.

Na contemporaneidade, uma das temáticas que mais parece tensionar o hábito de torcer - e, por extensão, as torcidas organizadas - são discussões ligadas às questões de gênero. Ao discutir a predominância de valores masculinos no futebol, Franzini (2005)

\footnotetext{
${ }^{10}$ TOLEDO. Políticas da corporeidade: sociabilidade torcedora entre 1990-2010, p.143.

11 TOLEDO. Políticas da corporeidade: sociabilidade torcedora entre 1990-2010, p. 138.

12 TOLEDO. Políticas da corporeidade: sociabilidade torcedora entre 1990-2010, p. 29.
} 
chama atenção para a ameaça que uma maior presença das mulheres nesse esporte tem significado para uma "ordem" ou "lógica" já estabelecida pelos homens. Na condição de torcedoras nos estádios, em especial nas partidas assistidas pelas elites no início do século $\mathrm{XX}$, as mulheres eram legitimadas por serem vistas como uma "parte ativa da consolidação do jogo por entre esses círculos elegantes".13 Uma maior participação fora da torcida, no entanto, em geral é vista como resistência pelos homens, que evocam argumentos como a "pouca experiência feminina na prática do jogo".14 Apesar disso, aponta essa autora, é notória a crescente presença feminina, por exemplo, através de facções de torcidas organizadas, mas também como consumidoras de produtos esportivos. Mais recentemente, chama atenção a emergência, especialmente na internet, de agrupamentos que evidenciam e questionam práticas discriminatórias no ato de torcer. É o caso das "torcidas queer", que

produzem e divulgam conteúdos com o propósito de colocar em xeque o padrão normatizador vigente nos estádios e no universo do futebol, reivindicando o reconhecimento da participação de homossexuais e mulheres, historicamente segregados de práticas que dão sentido ao esporte, como o jogar e o torcer. ${ }^{15}$

Criadas em 2013, as 11 torcidas queer brasileiras citadas por Pinto e Almeida (2014) atuam enquanto grupo apenas no Facebook, o que em parte se explica pelas constantes hostilidades e ameaçadas sofridas pelos criadores das páginas.

Longe de esgotar a temática, nessa breve discussão tentamos articular breve reflexões sobre as torcidas organizadas, suas lógicas de alinhamento e oposição e as tensões que as atravessam na contemporaneidade. Nosso intuito foi chamar a atenção para uma inadequação de um olhar para esses agrupamentos que os considere de forma estabilizada e isolada. Retomando o raciocínio de Latour (2012) e demais autores vinculados à Teoria Ator-Rede, parece-nos que, especialmente em ambientes interconectados como o Facebook e durante controvérsias, potencialmente os atores estão constantemente negociando suas alianças e filiações, como discutiremos empiricamente a seguir.

\footnotetext{
${ }^{13}$ COSTA. O que é uma torcedora?, p. 7.

${ }^{14}$ COSTA. O que é uma torcedora?, p. 4.

${ }^{15}$ PINTO; ALMEIDA. As torcidas queer em campo, p. 107.
} 


\section{METODOLOGIA E CORPUS DE PESQUISA}

Conceber pesquisas que considerem as especificidades dos ambientes digitais é um dos desafios de pesquisas como a aqui proposta. Rogers (2015) situa o esforço de desenvolvimento de "métodos digitais" de pesquisa junto ao esforço atual das ciências sociais e humanidades para incorporar a chamada "virada computacional" ("computational turn"). Uma das especificidades dos métodos digitais é pensá-los incorporados aos ambientes nos quais os dados estudados foram coletados, isto é, pesquisar ao mesmo tempo o ambiente tecnológico e o social que ali se forma, reconhecendo as afetações mútuas entre "meio" e "conteúdo" (Marres, 2015).

Especificamente os estudos de controvérsias, apontam Venturini e Latour (2009), "requerem um novo leque de métodos 'quali-quantitativos' que nos permitam rastrear os fenômenos sociais através nos processos de construção, desconstrução e reconstrução que o constituem". ${ }^{16}$ Os rastros digitais, conforme discute Fernanda Bruno (2012), podem ser tomados como inscrições de ações dos atores-rede, o que nos permite retraçar a composição de arranjos sociotécnicos e "tornar visíveis as controvérsias que animam uma série de fenômenos coletivos". ${ }^{17}$

Baseados nestas perspectivas, optamos, na primeira parte do trabalho empírico, por usar ferramentas computacionais que permitem a coleta e visualização de grandes volumes de dados. A observação panorâmica da atuação de um grande número de atores nos permitirá fazer uma análise quantitativa das associações entre eles para, em um segundo momento, nos voltarmos para uma discussão qualitativa de situações que nos parecerem mais representativas. Através da Application Programming Interface (API) do Facebook, extraímos com a ferramenta Netvizz (Rieder, 2013) dados relativos às postagens de cinco páginas de torcidas organizadas do Clube Atlético Mineiro. A ferramenta "Page Data" disponibiliza dados estruturados (tabelas e grafos) sobre um determinando conjunto de postagens e sobre os usuários que curtiram, comentaram ou compartilharam essas publicações. Os dados coletados referem-se a postagens entre 15 (dia do desfile) e 17 de fevereiro (dia da estreia do time na Copa Libertadores) e foram

\footnotetext{
${ }^{16}$ VENTURINI; LATOUR. The Social Fabric: Digital Traces and Quali-quantitative Methods, p. 5.

${ }^{17}$ BRUNO. Rastros digitais sob a perspectiva da teoria ator-rede, p. 703.
} 
extraídos no dia 24 de maio de 2016. As páginas e as postagens selecionadas sobre a controvérsia "Galo Machista"!? são:

GAlo MARX - segundo descrição na página do Facebook, esta torcida "nasce da união da luta pela emancipação dos trabalhadores com a sua paixão pelo futebol, precisamente pelo Atlético Mineiro". Dentre as cinco torcidas analisadas, foi a primeira a se manifestar sobre a controvérsia desencadeada pelo desfile: ainda na madrugada do dia 15 para 16 de fevereiro (1h06), foi postada uma "nota de repúdio" assinada pelas "Mulheres da Torcida Galo Marx".18 Esta nota foi a única postagem da Galo Marx no período analisado.

Torcida Organizada Galoucura - descrita em sua página no Facebook como a “MAIOR TORCIDA ORGANIZADA DE MINAS GERAIS!", a Galoucura postou às 11h36 do dia 16 uma mensagem de apoio à fornecedora de materiais esportivos Dry World . A imagem contém a frase "As organizadas do Galo desejam boas vindas à Dry World", traz fotos de modelos de biquíni e foi assinada por doze torcidas organizadas do Atlético. No post a torcida organizada escreveu: "Seja bem Vinda Dry World_BR DRYWORLD Industries!!! HONRAMOS O NOME DE MINAS Clube Atlético Mineiro \#AcreditoNaDryWorld \#DryworldÉGalo \#Galoucura". ${ }^{19}$ Nos três dias coletados, outras 21 postagens foram publicadas.

Torcida Organizada Galo Metal - autodefinida como a "primeira torcida organizada Metal do País, que une o rock'n'roll e o Clube Atlético Mineiro", a Galo Metal realizou 39 postagens no período coletado, com as quais 912 usuários diferentes interagiram. 0 post sobre a controvérsia postado às $12 \mathrm{~h} 35$ do dia seguinte ao desfile (dia 16) traz a mesma imagem de apoio à Dry World publicada pela Galoucura. No texto de descrição está escrito: \#AcreditoNaDryWorld \#DryWorldÉGalo \#UnidosPeloGalo. 20

Movimento 105 Minutos - A torcida organizada Movimento 105 Minutos se identifica como o "MAIOR MOVIMENTO BARRA BRAVA DE MINAS GERAIS". Às 13h27 do dia 16 o Movimento 105 minutos fez uma postagem sobre o tema, com o mesmo slogan das postagens das torcidas Galoucura e Galo Marx, porém sem a fotografia das modelos de biquíni. A partir da leitura de alguns comentários da postagem, percebemos que a

\footnotetext{
${ }_{18}^{18}$ Página do Facebook: Galo Marx.

${ }_{19}$ Página do Facebook: Torcida Organizada Galoucura.

${ }^{20}$ Página do Facebook: Torcida Organizada Galo Metal.
} 
página havia postado a imagem "completa" anteriormente, mas o post foi apagado quando a imagem foi tomada como ofensiva (fig. 1). ${ }^{21} \mathrm{~A}$ página da torcida 105 Minutos fez 11 postagens no intervalo dos três dias de coleta e, no momento da coleta dos dados, 1005 usuários diferentes haviam curtido, comentado ou compartilhado essas postagens.

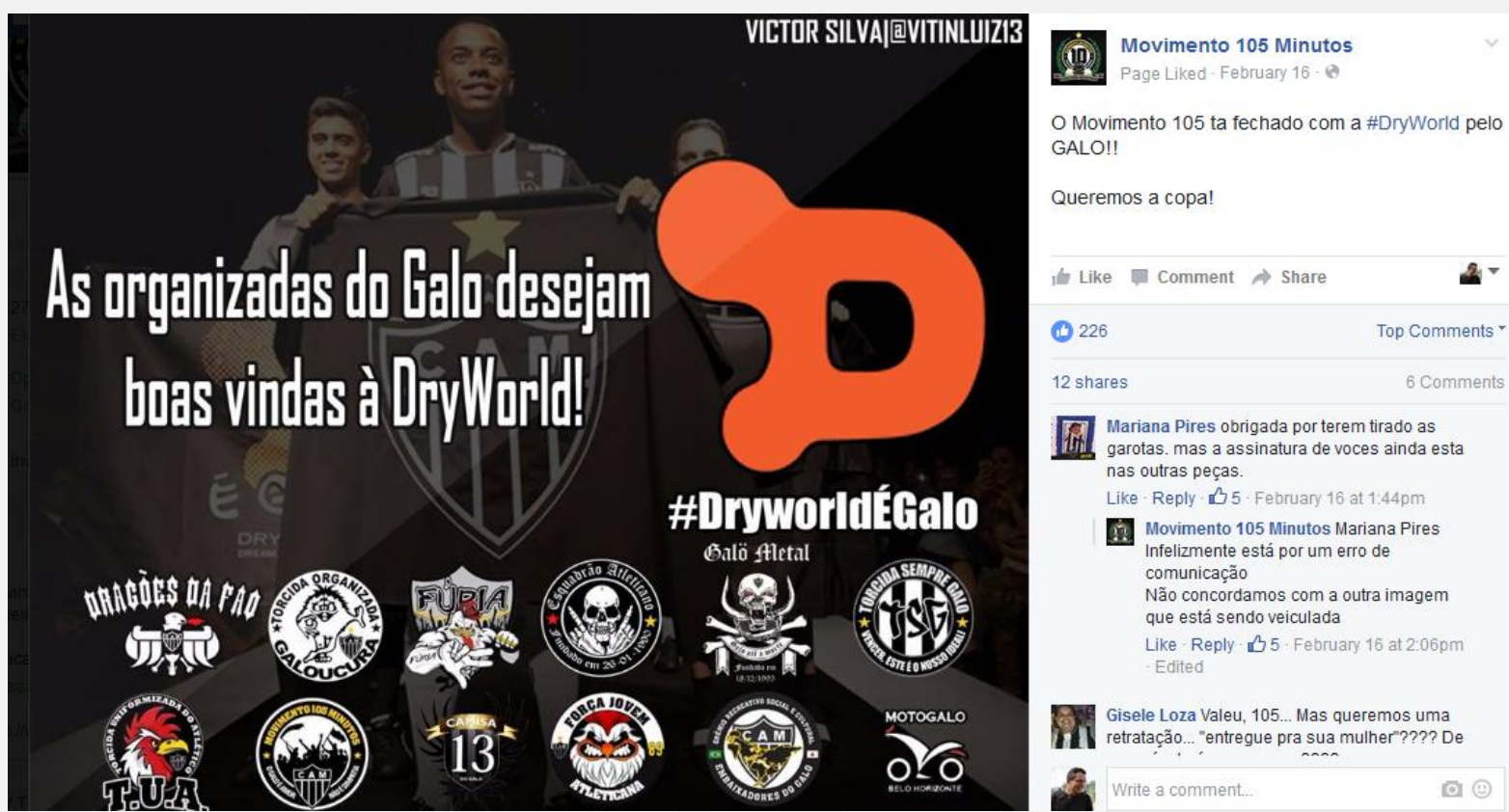

Fig. 1: print screen da postagem e comentários na página do "Movimento 105 Minutos".

Galo QUEER - Em sua página no Facebook, a Galo Queer se define como "o movimento anti-homofobia e anti-sexismo no futebol dos torcedores do Atlético Mineiro". No período coletado, realizou duas publicações e alcançou a interação de 440 usuários. Uma é o compartilhamento da nota de repúdio publicada pela Galo Marx, realizado no dia 16 de fevereiro às 9h33, e a outra é um texto de repúdio ao desfile da nova coleção de uniformes, publicado no mesmo dia às 16h39. Este texto (que foi selecionado para análise a seguir) afirma que "Amor pelo Galo não tem nada a ver com machismo. Fica nosso repúdio a todas as partes envolvidas na concepção e realização desse desfile e à empresa Dry World." e repudia a objetificação feminina e a hipersexualização de adolescentes. Além disso, critica a etiqueta que diz "dê à sua esposa" nas instruções de lavagem da camisa. A imagem que ilustra a publicação é de duas modelos desfilando de biquíni. ${ }^{22}$

\footnotetext{
${ }^{21}$ Página do Facebook: Movimento 105 Minutos.

${ }^{22}$ Página do Facebook: Galo Queer.
} 


\section{RASTROS E TRANSLAÇÕES NAS POSTAGENS: UMA VISÃO PANORÂMICA}

Nosso primeiro esforço analítico foi de compreender as especificidades dos rastros (curtidas, comentários e compartilhamentos) deixados nas postagens sobre a controvérsia em relação às demais postagens feitas pelas páginas nos três dias analisados. Para isso, geramos no software Gephi uma visualização com os dados relativos às cinco páginas (fig. 2).

$\mathrm{Na}$ visualização, os nós na cor lilás referem-se aos usuários que curtiram, comentaram e/ou compartilharam algumas das postagens, enquanto os demais nós se referem às cinco postagens sobre a controvérsia (cores conforme legenda na fig. 2) ou às demais postagens do período (coloridos de cinza). 0 tamanho dos nós varia de acordo com o grau, isto é, os nós maiores referem-se às postagens que receberam mais curtidas, comentários ou compartilhamentos. Ao todo o grafo da figura 2 contém 60 posts e 9.274 usuários que interagiram 16.855 vezes com essas postagens.

Para gerar essa visualização, foi aplicado a distribuição Force Atlas 2, um layout em que a espacialização visual da rede está relacionada à intensidade das associações entre os nós (Jacomy; Venturini; Heymann; Bastian, 2014). Assim, ficam mais próximos entre si os nós que se vinculam às mesmas arestas e tornam-se periféricos os nós que têm menos ligações com o restante do grafo.

A figura 2 nos permite identificar uma significativa polarização entre as redes em torno das postagens da Torcida Organizada Galoucura (à esquerda) e as das torcidas Galo Marx e Galo Queer (à direita). Já as postagens das torcidas Galo Metal e, em especial, Movimento 105 Minutos estão posicionadas mais ao centro do grafo, o que sinaliza que um número maior de usuários agiu tanto nessas quanto em algumas das outras páginas estudadas, tornando-se atores potencialmente mais articulados nas discussões em torno das controvérsias.

É importante notar, no entanto, que a postagem da Galoucura sobre a controvérsia é, dentre as 22 publicadas no período, a que espacialmente mais se aproxima das redes de rastros em torno das demais páginas. 0 fato do nó roxo que representa esta postagem estar mais próxima do centro do grafo indica que mais usuários que se associaram a esse post também se engajaram com outras páginas. Já a postagem da torcida Galo Metal (nó vermelho) sobre a controvérsia se aproxima mais 
das redes em torno das páginas Galo Marx e Galo Queer do que as demais postagens, o que também sinaliza um maior trânsito de usuários em função das associações desencadeadas pela controvérsia.

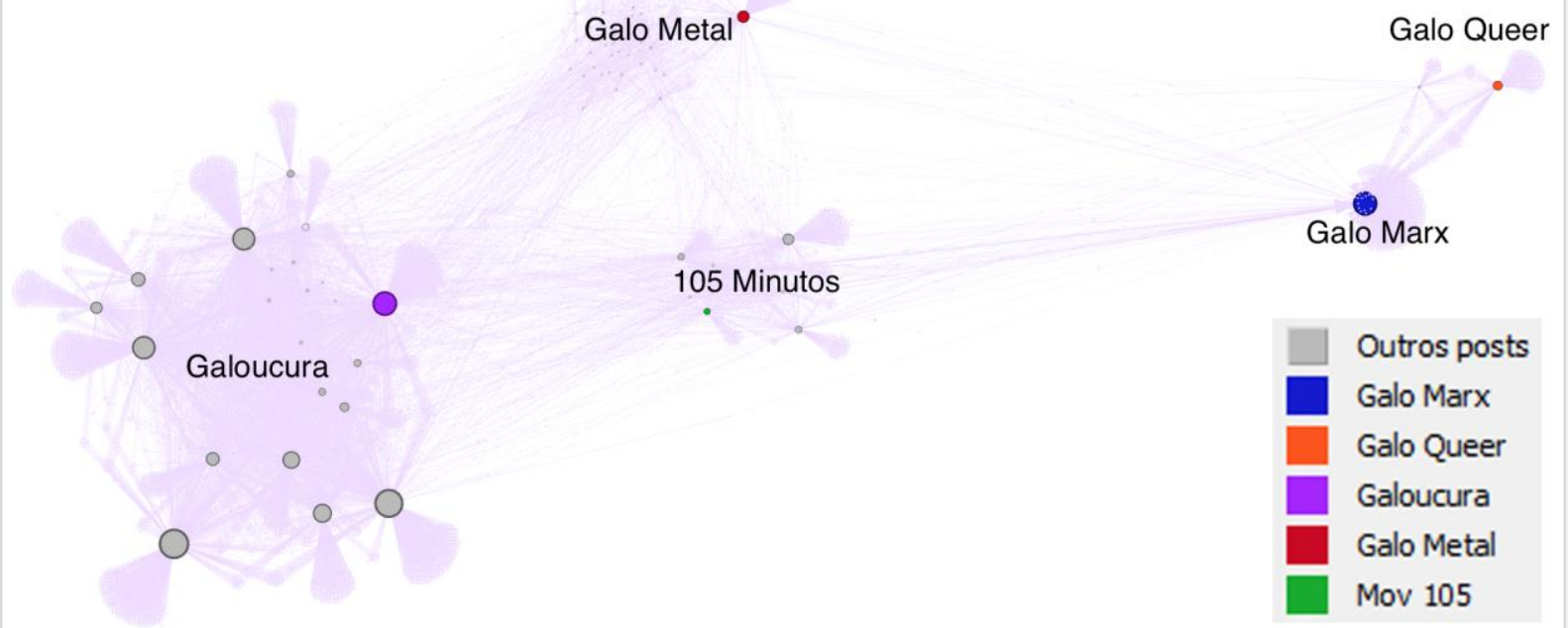

Fig. 2: grafo com as redes de interações das postagens publicadas entre 15 e 17 de fev.

Em termos gerais, portanto, a figura 1 nos indica que embora haja uma significativa polarização nas redes formadas em torno das postagens sobre as controvérsias, estas postagens alavancaram um maior trânsito de atores do que as demais publicadas no período de três dias aqui estudados. A visualização dos rastros digitais de curtidas, comentários e compartilhamentos nos sinaliza que as translações motivadas pela controvérsia culminaram na formação de novos agrupamentos em torno das postagens.

Para nos aproximarmos mais das repercussões da controvérsia “Galo Machista”!? nas páginas das torcidas organizadas, nos concentramos então na principal postagem de cada página sobre o tema. Gerado no software Tableau Public, o gráfico da figura 3 nos permite visualizar, em função do tamanho do círculo, o volume de curtidas, comentários e compartilhamentos dos posts sobre a controvérsia. Os posts estão distribuídos no eixo horizontal do gráfico de acordo com o horário de publicação.

Na figura 3, identificamos um maior agrupamento em torno da "nota de repúdio" publicada pela página Galo Marx - ao todo, essa postagem recebeu 1007 curtidas, 574 comentários e 266 compartilhamentos. A postagem da Torcida Galoucura, embora tenha sido mais curtida (1118), gerou bem menos discussões (63 comentários). A mesma 
imagem publicada pela Galo Metal foi menos curtida (470) mas mais comentada (84) que a da Galoucura.

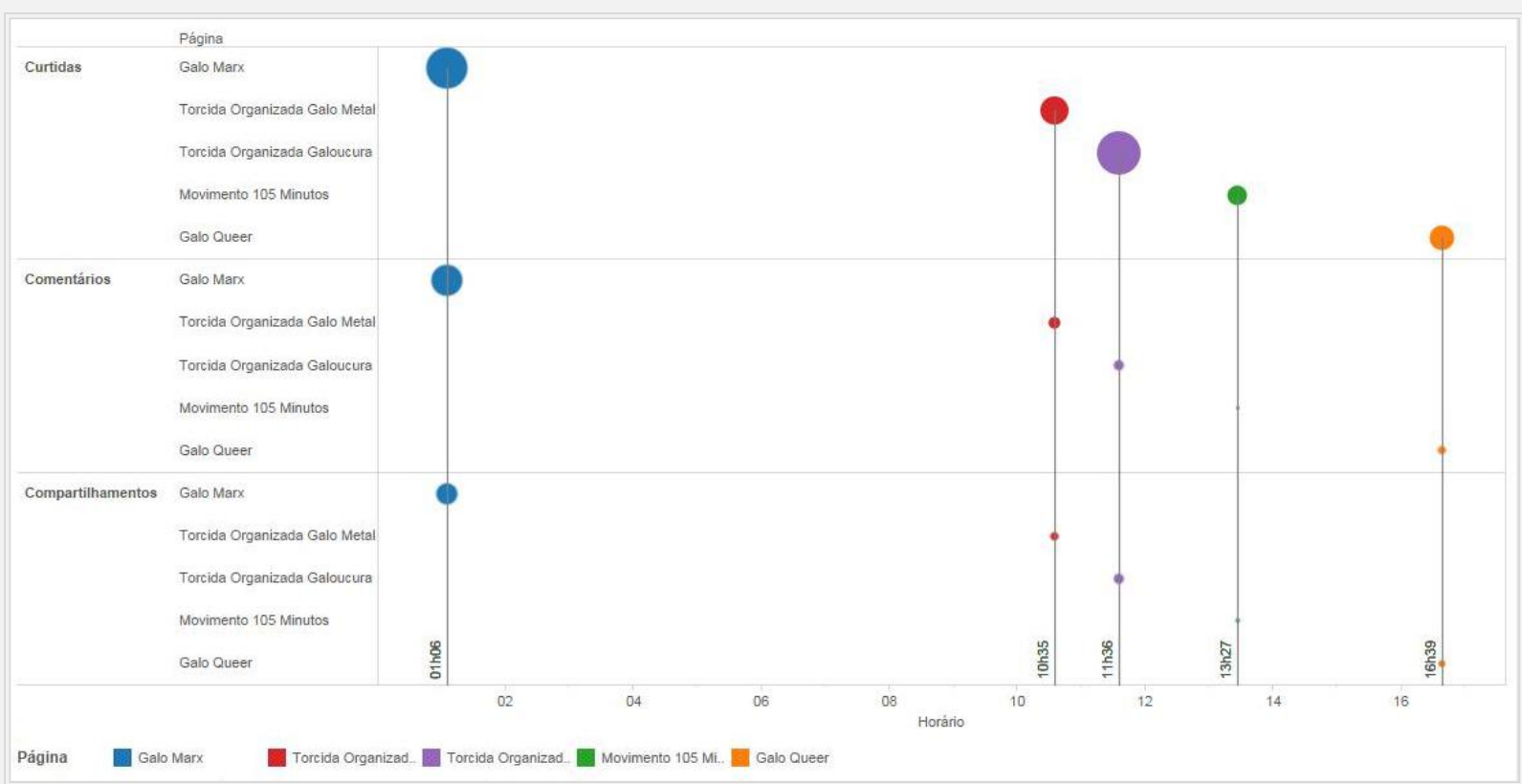

Fig. 3: curtidas, comentários e compartilhamentos nos posts sobre o desfile nas págs. analisadas.

Tal constatação fica mais clara se observarmos os dados relativos a "respostas de comentários" e "curtidas em comentários" disponíveis na figura 4. Retomando o esforço metodológico de compreender as controvérsias nas redes sociais on-line em diálogo com as ambiências sociotécnicas em que elas se efetivam, como discutimos no referencial teórico, consideramos que esses dois tipos de rastros extraídos do Facebook podem ser tomados como indícios de engajamento dos atores-rede nas controvérsias, uma vez que sinalizam uma disposição em discutir argumentos específicos (através das "respostas de comentários") e/ou de apoiar a posição de alguém ("curtidas em comentários").

De forma ainda mais destacada, na figura 4 a postagem da página "Galo Marx" destaca-se em termos quantitativos. Ao todo, os comentários da "Nota de Repúdio" foram curtidos 1570 vezes e, dos 574 comentários, 350 (ou 61\%) foram respostas. Já na postagem da "Galo Metal", 38 dos 84 comentários (45,23\%) foram respostas. 


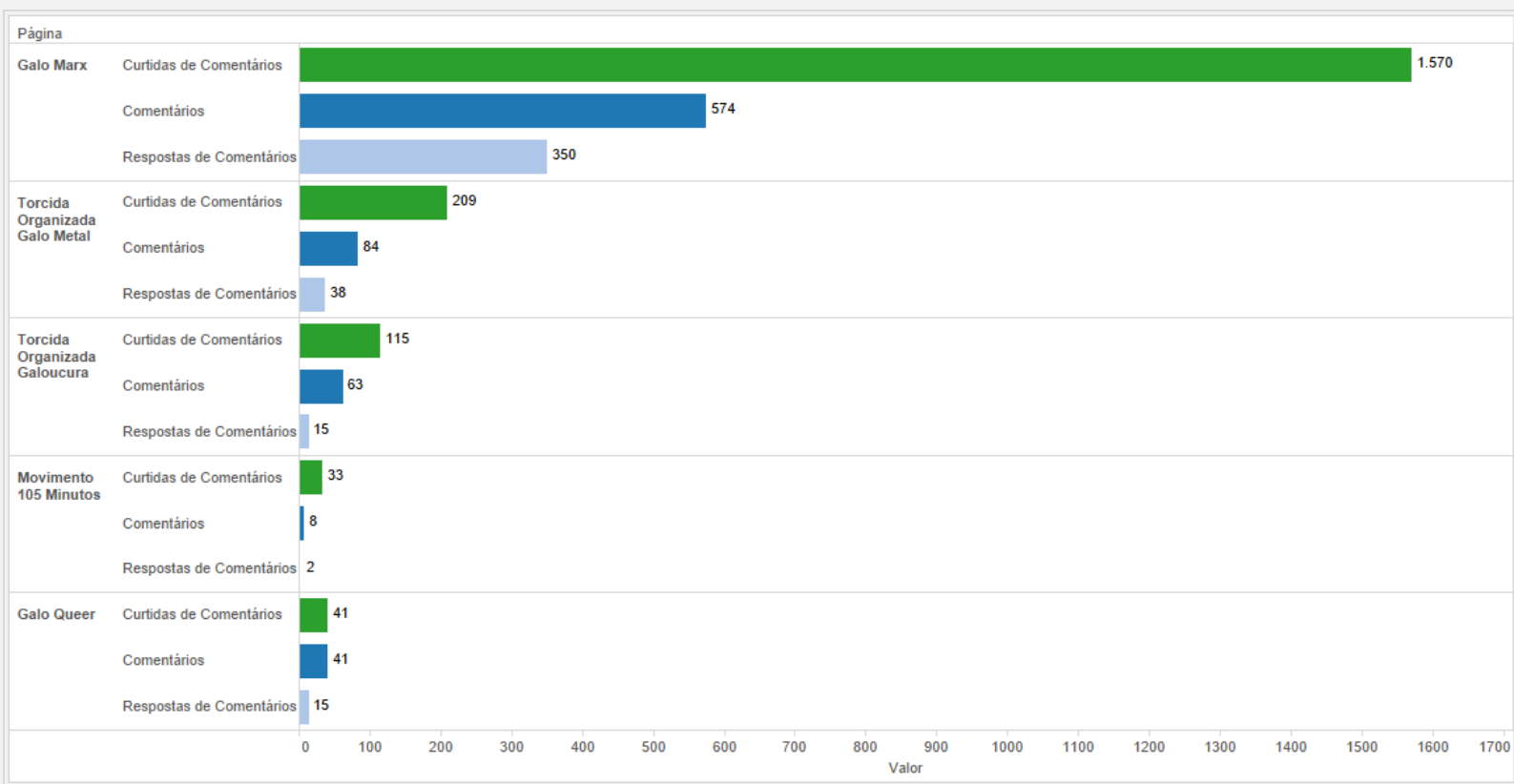

Fig. 4: curtidas de comentários, total de comentários e respostas a comentários nas postagens sobre o desfile.

\section{ANÁLISE DAS DisCuSSõES NAS POSTAGENS dA GALO MARX}

Assinada pelas Mulheres da Torcida Galo Marx, a "nota de repúdio" denuncia a objetificação das mulheres, uma vez que "as modelos femininas estavam presentes, aparentemente, apenas para o prazer masculino". Entre outras questões, as signatárias afirmam que as mulheres não devem "ser representadas como para o deleite de homens que se julgam o grande 'público-alvo' do futebol", e repudiam "a adultização de uma modelo adolescente trajando calcinha", "a sexualização do corpo feminino" e "a cultura do estupro refletida e reforçada no desfile". A nota lembra ainda o papel histórico das mulheres na construção de um clube que se diz 'do povo' e critica o viés econômico do futebol moderno "em que machismo e capitalismo andam juntos".

Alguns dos comentários mais curtidos da postagem foram feitos por torcedoras de outros times - inclusive do arquirrival Cruzeiro -, que manifestaram apoio à nota de repúdio da Galo Marx (fig. 5). 


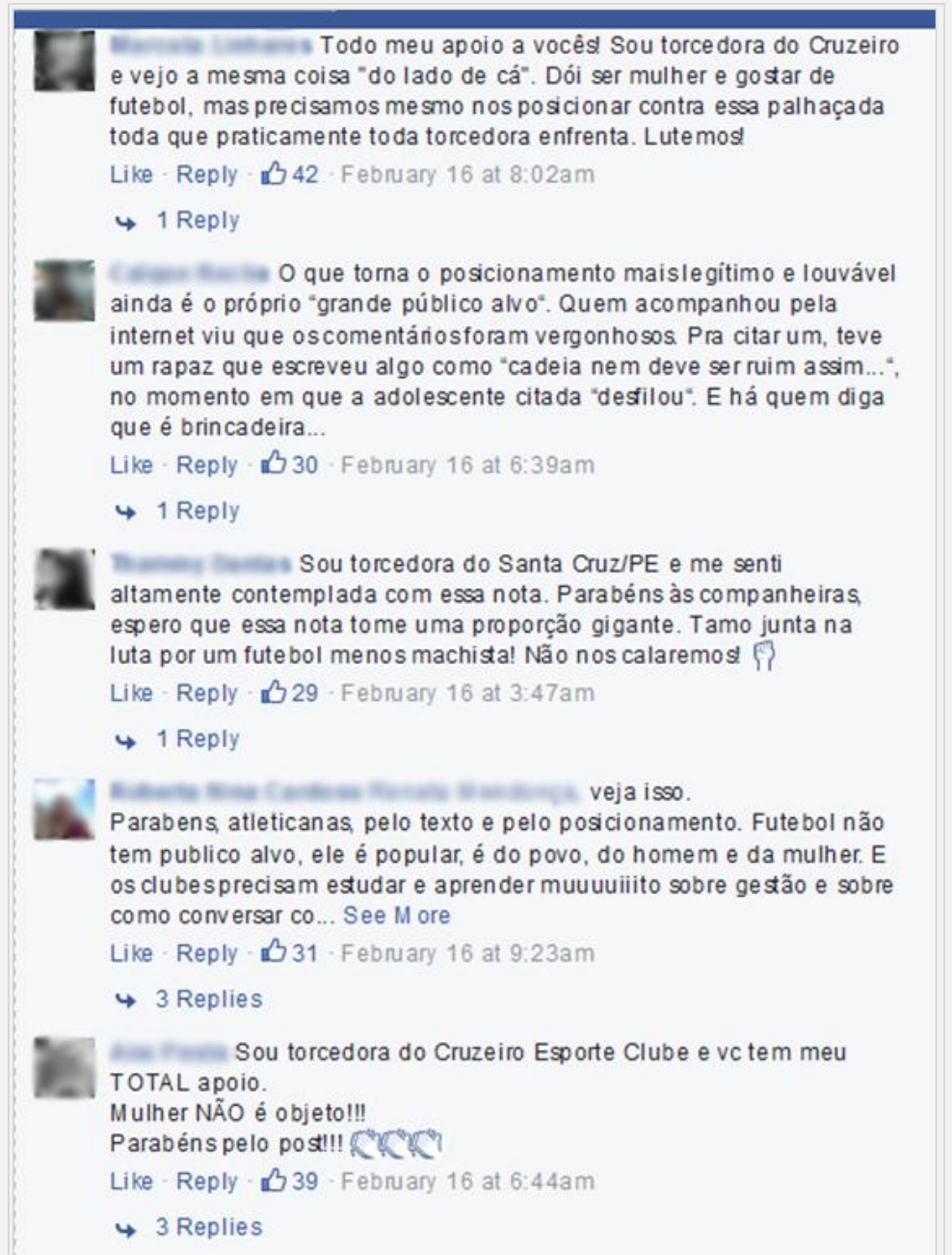

Fig. 5: comentários mais curtidos da postagem da Galo Marx.

Um dos comentários que mais receberam respostas foi dado pela mesma torcedora do Santa Cruz/PE citada na figura 5. Em sua argumentação, a comentarista chama a atenção para "a quantidade de pessoas que estão do nosso lado", em uma referência aos apoiadores da nota de repúdio publicada pela Galo Marx (fig. 6).

As discussões desencadeadas por esse comentário giram em torno principalmente da relação entre mulheres e futebol, com destaque para a importância da jogadora Marta. 0 comentário mais curtido (8) dessa sequência foi feito por um torcedor que toma outro comentário anterior como indício de que "nós homens não conseguimos ser superiores em nada". No comentário criticado, outro torcedor afirmara que "Não adianta, no futebol os homens sao anos luz superiores as mulheres" (sic). 


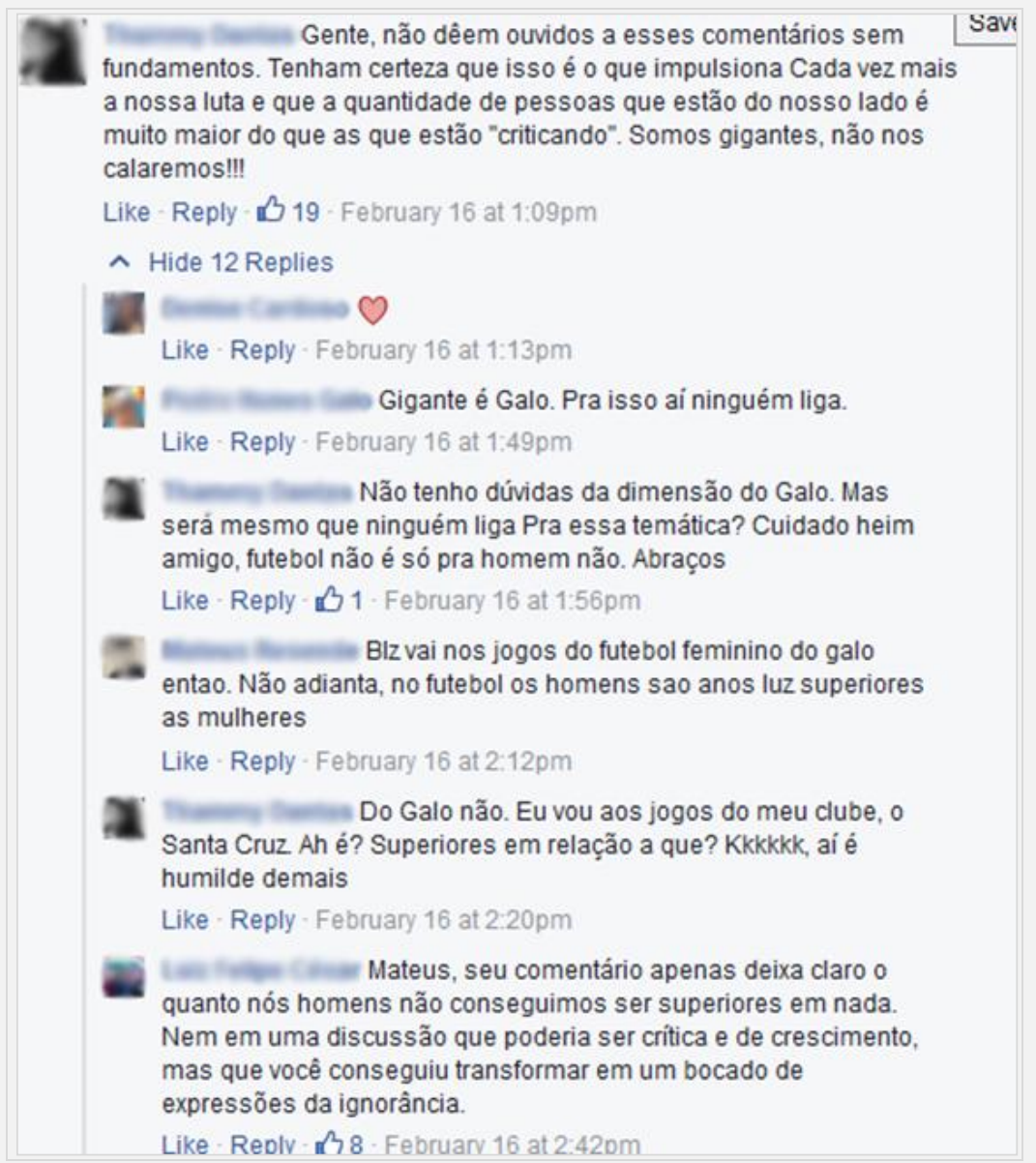

Fig. 6: parte das respostas a um comentário da postagem da Galo Marx.

Outros comentários que desencadearam mais respostas discordaram na "nota de repúdio" publicada pela Galo Marx. Depois que uma torcedora afirmou que "eu também não acho correto esse tipo de coisa... Mas engraçado... As feministas que reclamam são as mesmas que saem sem roupa na rua se chamando de vadias..., a maioria das 21 respostas a esse comentário procurou desconstruir o argumento. Acusada de ser machista e de defender a objetificação do corpo da mulher, a autora do comentário inicial, mesmo tentando com frequência encerrar a discussão, respondeu com novos argumentos, defendendo, por exemplo, a livre escolha das modelos que desfilaram.

A liberdade das modelos para desfilarem "de lingerie nas passarelas" também foi um dos argumentos de outro comentário que discordou da postagem da Galo Marx. O autor afirma não negar a existência do machismo, mas acredita que a crítica ao desfile é uma tentativa de impor "regras morais sem sentido", inclusive porque uma atriz desfilara “totalmente pelada” durante o Carnaval do Rio de Janeiro alguns dias antes (fig. 7). 


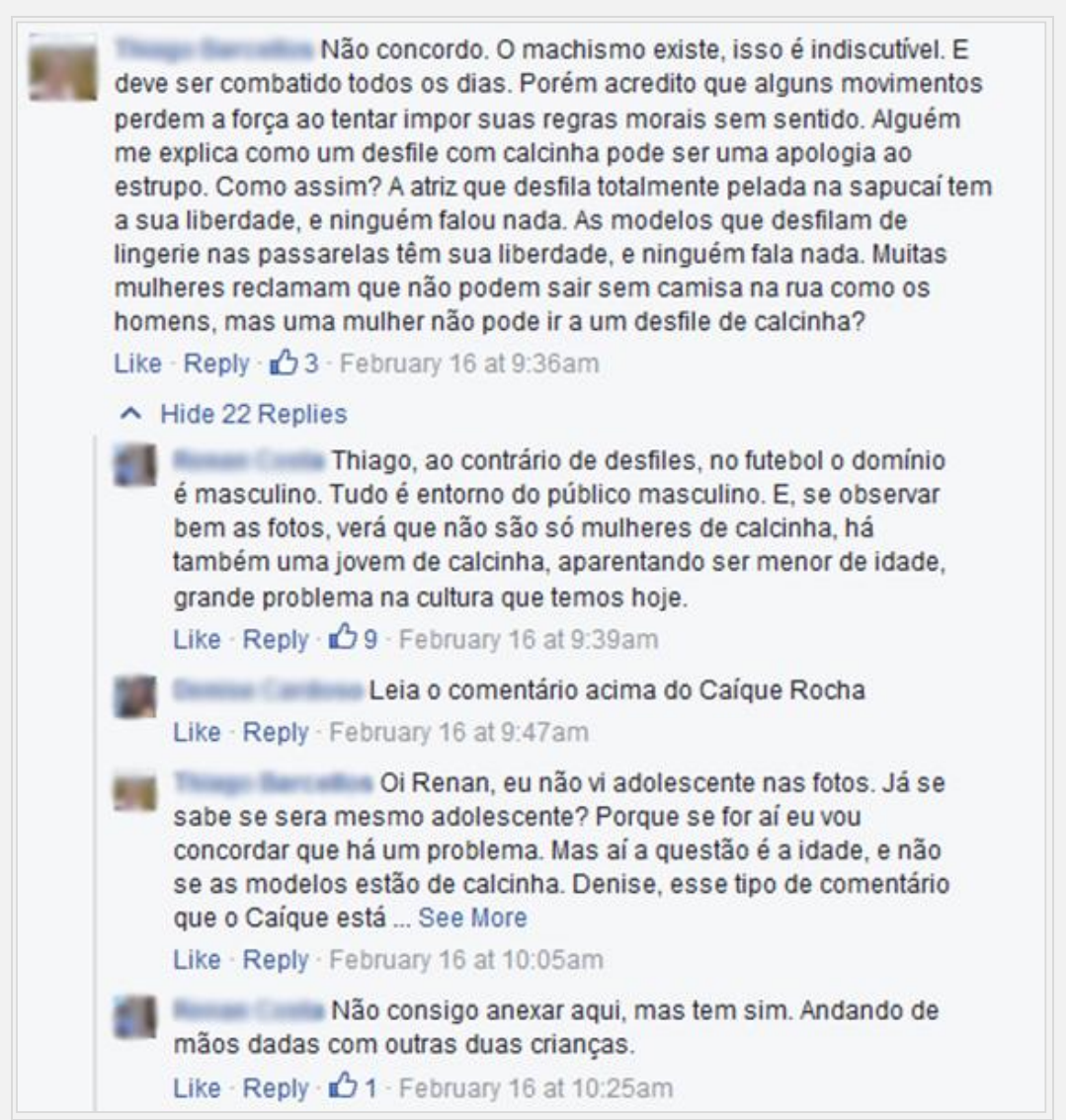

Fig. 7: parte das respostas a um comentário da postagem da Galo Marx.

Este comentário desencadeou 22 respostas. 0 mais curtido deles (9) também foi feito por um homem, que contra-argumentou destacando o "domínio" masculino no futebol e denunciando a presença de uma jovem aparentemente menor de idade entre as modelos que desfilaram de calcinha.

O comentário que mais desencadeou respostas, no entanto, não teve ligação direta com as questões de gênero que motivaram a nota de repúdio da torcida organizada. Um usuário criticou o fato da Galo Marx usar como símbolo "um cara que era homofóbico e antissemita". A acusação desencadeou uma sequência de 46 comentários, a maioria dos quais criticando a afirmação inicial, em uma discussão que mobilizou argumentos em torno das ideias e da origem judia de Karl Marx. No argumento mais curtido, um usuário disse: "MARX ERA JUDEU CARA, NÃO FALA BOBAGEM". 


\section{ANÁLISE DAS DISCUSSÕES NAS POSTAGENS DA GALO METAL}

A postagem da torcida Galo Metal sobre a controvérsia foi a segunda com maior número de comentários: 84. Como descrevemos anteriormente, trata-se de uma peça de boas-vindas e apoio à Dry World assinada por 12 torcidas organizadas. Compõem a postagem fotos de duas modelos desfilando de biquíni e uma vestida com a camisa do time e calcinha.

Um mesmo comentário foi o que recebeu mais curtidas e respostas. Nele, a autora afirma "machistas não passarão \#vergonha \#bolafora". Nas respostas, a maioria dos usuários se coloca de forma contrária à comentarista (fig. 8).

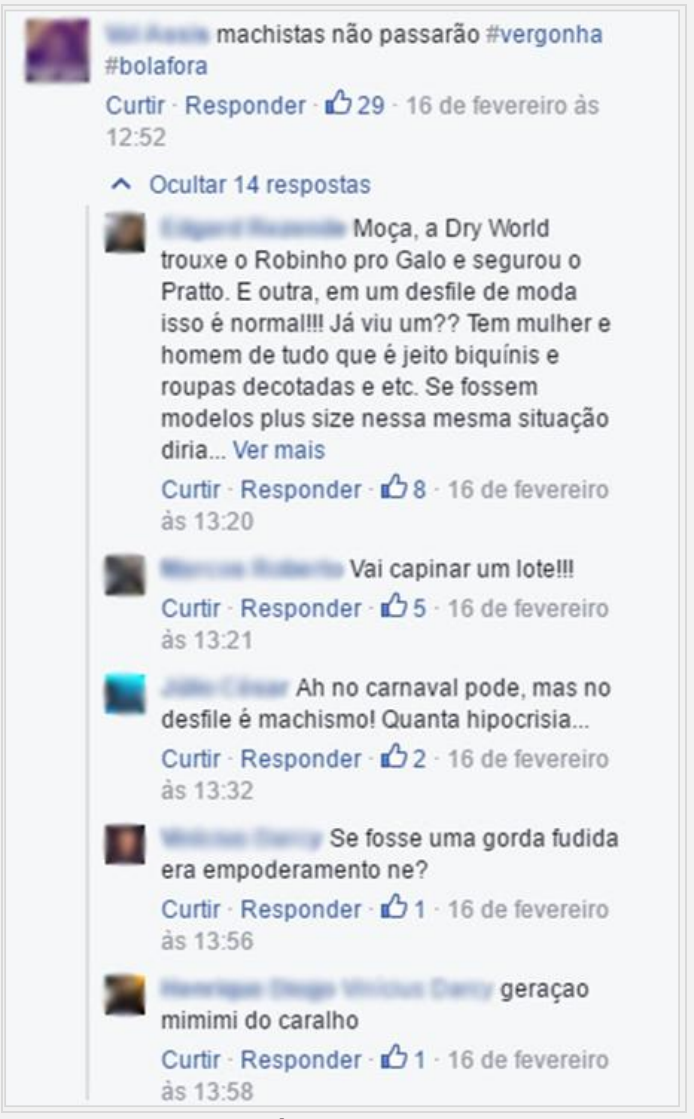

Lamentável ver vocês compartilhando essa imagem e compactuando com esse tipo de atitude. Muito triste mesmo. Curtir - Responder $\cdot \mathbf{B} 14 \cdot 16$ de fevereiro às $14: 47$

$\wedge$ Ocultar 13 respostas

1 moça, a Dry World trouxe o Robinho pro Galo e segurou o Pratto. E outra, em um desfile de moda isso é normal!!! Jà viu um?? Tem mulher e homem de tudo que é jeito biquínis e roupas decotadas e etc. Se fossem modelos plus size nessa mesma situação diriam que o time é progressista e tal. Não é verdade ??? Por acaso ser bonita agora virou um desmerito!! Absurdo. E tem mais: mulheres desfilaram de calção também e TODAS as pecas serão vendidas inclusive o biquini. Nao e questão de machismo e sim bom senso. Então para de tentar queimar a marca que está ajudando esse clube dentro e fora de campo e vai arrumar o que fazer além de falar essas baboseiras na internet.

Curtir - Responder - 33 - 16 de fevereiro às 23:04

Fig. 9 - resposta a comentário replicada na postagem da Galo Metal.

Fig. 8: comentário mais curtido e comentado da postagem da Galo Metal.

As respostas reclamam que os posicionamentos contrários ao desfile por conta de seu teor machista são apenas "mimimi" e que, em outras circunstâncias, como no carnaval ou caso fossem modelos gordas, o fato de as mulheres estarem vestidas como estavam não desencadearia tantas discussões. 0 comentário mais curtido (8) também defende a marca, apontando que ela "trouxe o Robinho pro Galo e segurou o Pratto". 
Outro comentário com grande engajamento mostra um desapontamento com Galo Metal por causa do posicionamento tomado a partir da publicação. Nas 13 respostas, o mesmo texto do comentário que recebeu mais curtidas analisado anteriormente foi reproduzido (sem veicular os créditos) por outro torcedor (fig. 9).

Nesse caso, porém, a resposta mais curtida é da mesma autora do comentário principal. Ela afirma que não iria omitir seu posicionamento só por conta dos benefícios trazidos pela marca, que as mulheres sofrem assédio nos estádios e que desfiles de moda são tão opressores quanto o realizado pela Dry World e que, por conta disso, não devem ser usados como justificativa. Além disso, ela diz que "A mensagem a ser transmitida [pelo desfile] foi 'mulheres sensuais com a camisa do clube do atlético mineiro'”, já que a exposição dos corpos das mulheres apareceu não apenas no desfile de biquínis, mas também no de camisas. Após uma resposta do mesmo usuário falando sobre a importância de se focar na estreia do Atlético na Copa Libertadores, outra comentarista defende que os atleticanos não se tornam menos torcedores ao notarem os erros do time, e que a Dry World não concedeu favores ao time, já que "trata-se de uma parceria e, como tal, ambos saem ganhando".

Nessa postagem, aparecem ainda várias torcedoras afirmando que irão "descurtir" a página por causa de uma insatisfação com o posicionamento da torcida (fig. 10).

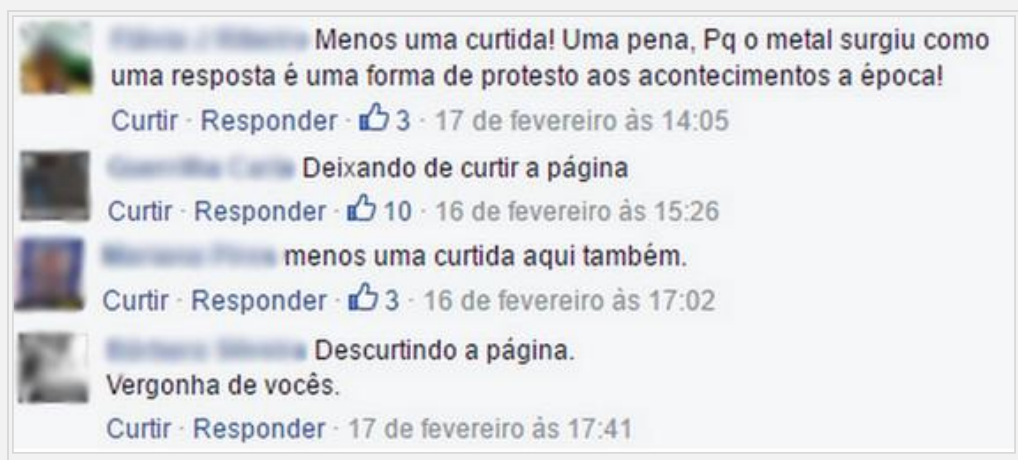

Fig. 10: comentários na postagem da Galo Metal. 


\section{DISCUSSÃO DOS DADOS E CONSIDERAÇõES FINAIS}

Procuramos neste trabalho identificar e discutir a repercussão da controvérsia "Galo Machista"!? na página do Facebook de cinco torcidas organizadas do Clube Atlético Mineiro. Mais especificamente, procuramos observar como a controvérsia desencadeou a formação de grupos e alianças entre diferentes usuários do Facebook.

A partir dos dados quantitativos apresentados no trabalho, podemos apontar que as associações em torno das postagens sobre a controvérsia tiveram uma dinâmica diferente das demais postagens das páginas no período analisado. Em geral as postagens sobre o tema não apenas foram mais curtidas, compartilhadas e/ou comentadas que as demais, mas principalmente motivaram a agência de usuários diferentes das demais postagens. Essa relativa variação nos usuários engajados nas postagens pode ser visualizada na figura 2, que sinaliza ainda que a desestabilização promovida pela controvérsia desencadeou mais translações entre os atores e permitiu a formação de agrupamentos que tensionam uma dinâmica mais rotineira das páginas.

É especialmente peculiar a posição ocupada pela "nota de repúdio" publicada pela torcida Galo Marx. Embora se destaque em termos quantitativos, a postagem é periférica no grafo, o que indica que os usuários que se engajaram no post não foram os mesmos das demais páginas (à exceção da Galo Queer, que está espacialmente próxima na visualização). Essa característica nos permite supor que o grande número de compartilhamento da postagem fizeram-na repercutir por um público que habitualmente não segue a página da Galo Marx ou as demais páginas estudadas. Essa maior circulação da postagem do Facebook certamente impactou na dinâmica da discussão na caixa de comentários e desencadeou novas translações entre os atores.

Para pensarmos nos processos de formação de grupos em eventos controversos, é importante observar que, na nota de repúdio da Galo Marx, oposições que poderiam ser tomadas como dadas, como "torcedores do CAM x torcedores do Cruzeiro e outros times" e "homens x mulheres", não foram predominantes a partir das associações visibilizadas pelos comentários mais respondidos ou mais curtidos. Em geral a adesão ou não a um comentário se deu em função do posicionamento em relação à controvérsia (favoráveis ou contrários ao desfile ou à nota de repúdio). Assim, torcedores de outros times apoiaram a iniciativa e homens se opuseram a outros homens em defesa de 
argumentos apresentado por mulheres que apoiavam o repúdio da Galo Marx. Nessa cadeia de translações identificada na caixa de comentários, nos parece representativo o esforço de uma torcedora do Santa Cruz para demarcar, através de expressões com "nossa luta" e "somos gigantes", um agrupamento de críticos ao desfile e às tentativas de relativizar a implicações das ações do time e da empresa.

Já nas discussões em torno da postagem da página Galo Metal nota-se uma grande adesão (traduzida em curtidas) às críticas feitas por torcedoras ao desfile e aos apoios dados à patrocinadora. 0 argumento de oposição que mais recebeu apoio, no entanto, não apenas tenta esvaziar as críticas, mas principalmente justifica a necessidade de encaixapretar a controvérsia em função do apoio financeiro da fornecedora ao time. Essa tentativa de silenciamento se dá também por um isolamento das mulheres que se posicionaram na página da Galo Metal. Ao contrário da Galo Marx, nessa página não se evidenciou o apoio de homens às críticas feitas por torcedoras, uma vez que os comentários delas ou de apoio a elas foram pouco curtidos e suas manifestações tenham sido mais intensamente debatidas, ou contestadas. A polarização entre um apoio irrestrito ao time por questões econômicas e/por por paixão ao time e um questionamento em função de posturas políticas, assim, parece revelar também uma cisão entre torcedoras e torcedores. A algumas delas, a alternativa parece ter sido "descurtir", ou melhor, sair da rede articulada pela página tornando pública esta decisão.

Acreditamos que a discussão empreendida nesse artigo nos releva algumas tensões das diferentes formas de torcer na contemporaneidade. No mesmo sentido, as discussões em torno da controvérsia e as formações de grupo pode elas desencadeadas nos ajudam a compreender o machismo e outras práticas excludentes no futebol, sinalizando questões importantes a serem aprofundadas em estudos futuros.

\section{REFERÊNCIAS}

BRUNO, Fernanda. Rastros digitais sob a perspectiva da teoria ator-rede. Famecos, Porto Alegre, vol. 19, n. 3, set.-dez. 2012, p. 681-704.

CALLON, Michel. Some Elements of a Sociology of Translation: Domestication of the Scallops and the Fishermen of Saint Brieuc Bay. In: LAW, John (org). Power, Action and Belief: a new Sociology of Knowledge?. Londres: Routledge and Kegan Paul, 1986, p. 196-233. 
CALLON, Michel; LASCOUMES, Pierre; BARTHE, Yannick. Acting in an uncertain world: an essay on technical democracy. Graham Burchell, Massachusetts, MIT Press, 2011.

CAMPOS, Elen. Nota de repúdio: machismo em evento do Galo. UOL. Acesso em: 19 ago. 2016. Disponível em: https://goo.gl/QUa0Xg.

COSTA, Leda Maria da. O que é uma torcedora? Notas sobre a representação e autorrepresentação do público feminino de futebol. Esporte e Sociedade, Rio de Janeiro, vol. 2, n. 4, nov.,2006-fev. 2007, p. 1-31.

FRANZINI, Fábio. Futebol é "coisa para macho"? Pequeno esboço para uma história das mulheres no país do futebol. Revista Brasileira de História, São Paulo, vol. 25, n. 50, dez. 2005, p. 315-328.

FREIRE, Letícia de Luna. Seguindo Bruno Latour: notas para uma antropologia simétrica. Comum, Rio de Janeiro, vol. 11, n. 26, jan.-jun. 2006, p. 46-65.

GERLITZ, Carolin; HELMOND, Anne. The like economy: Social buttons and the dataintensive web. New media \& society, vol. 8, n. 15, dez. 2013, p. 1348-1365.

JACOMY, Mathieu; VENTURINI, Tommaso; HEYMANN, Sebastien; BASTIAN, Mathieu. ForceAtlas2, a Continuous Graph Layout Algorithm for Handy Network Visualization Designed for the Gephi Software. Califórnia, PLOS ONE, vol. 9, n. 6, jun. 2014.

LATOUR, Bruno. Reagregando o social: uma introdução à teoria do ator-rede. Gilson Cesar Cardoso de Sousa, Salvador - São Paulo: Edufba - Edusc, 2012.

LEMOS, André. A comunicação das coisas: teoria ator-rede e cibercultura. São Paulo: Annablume, 2013.

MARRES, Noortje. Why Map Issues? On Controversy Analysis as a Digital Method. Science Technology Human Values, vol. 40, n. 5, set. 2015, p. 655-686.

MARRES, Noortje; MOATS, David. Mapping Controversies with Social Media: The Case for Symmetry. Social Media + Society, vol. 1, n 2, jul.-dez. 2015, p. 1-17.

PINTO, Mauricio Rodriguez; ALMEIDA, Marco Bettine. As torcidas queer em campo: a emergência de grupos que questionam a homofobia e o machismo no futebol. Revista Brasileira de Estudos do Lazer, Belo Horizonte, vol. 1, n. 2, ago. 2014, p.105-116.

RIEDER, Bernhard. Studying Facebook via Data Extraction: The Netvizz Application. WebSci'13, França, vol. , n. mai./2013, p. 346-355.

ROGERS, Richard. Digital Methods for Web Research. In: SCOTT, Robert; KOSSLYN, Stephen. Emerging Trends in the Social and Behavioral Sciences. Chichester, SAGE Publications, 2015, p. 1-18.

ROGERS, Richard; SÁNCHEZ-QUERUBIN, Natalia; KIL, Aleksandra. Issue Mapping for an Ageing Europe. Amsterdam: Amsterdam University Press, 2015.

SILVA, Silvio. Ricardo da. Torcedores Organizados em Belo Horizonte. In: SILVA, Silvio; DEBORTOLLI, José Alfredo; SILVA, Tiago Felipe da (orgs). O Futebol nas Gerais. Belo Horizonte: Ed. UFMG, 2012, p. 25-50. 
TOLEDO, Luiz Henrique. Políticas da corporeidade: sociabilidade torcedora entre 1990-2010. In: HOLLANDA, Bernardo Borges Buarque de; MALAIA; João M. C; MELO, Victor Andrade de (orgs). A torcida brasileira. Rio de Janeiro: 7Letras, 2012, p.122-158.

VENTURINI, Tommaso. Diving in magma: how to explore controversies with actornetwork theory. Public Understanding of Science, Chichester, vol. 19, n. 3, maio 2010, p. 258-273.

VENTURINI, Tommaso; LATOUR, Bruno. The Social Fabric: Digital Traces and Quali-quantitative Methods. In: Proceedings of Future En Seine. França: Cap Digital, 2009, p. 87-104.

\section{PÁGINAS DO FACEBOOK}

Galo Marx. https://goo.gl//BWk8E.

Galo Queer: https://goo.gl/0i2Nk1.

Movimento 105 Minutos: https://goo.gl/EsoG1E.

Torcida Organizada Galo Metal. https://goo.gl/sG3JKj.

Torcida Organizada Galoucura. https://goo.gl/pZkgxr. 